DOI: $10.14451 / 1.184 .152$

\title{
АЛЖИРСКАЯ НАРОДНАЯ ДЕМОКРАТИЧЕСКАЯ РЕСПУБЛИКА В СИСТЕМЕ ЭНЕРГЕТИЧЕСКОЙ БЕЗОПАСНОСТИ ЕВРОПЕЙСКОГО СОЮЗА
}

\author{
(c) 2020 Моногаров Николай Николаевич \\ Санкт-Петербургский государственный экономический университет, Россия, Санкт-Петербург \\ E-mail: monogarov_nik@mail.ru
}

В статье рассматриваются вопросы, посвященные современным проблемам энергетической безопасности стран Европейского союза, а также необходимости создания для этих стран единой энергетической концепции. Особые акценты в статье сделаны на растущей энергетической зависимости стран ЕС от импорта энергоресурсов, где особый статус принадлежит Алжирской Народной Демократической Республике.

Ключевые слова: Европейский союз, энергетическая безопасность, энергетические ресурсы, энергетическое сотрудничество, энергетическая концепция.

Одним из условий устойчивого развития и экономической стабильности Европейского Союза в современных условиях, безусловно, является энергетическая безопасность и внешнеполитическая стабильность, которая, в свою очередь, непосредственно зависит от степени энергетической безопасности. Особое внимание к феномену энергетической безопасности было уделено после первого и на сегодняшний день считающийся самым сильным нефтяным кризисом (1973 год), после которого многие государства импортеры энергоресурсов стали задумываться о стратегических резервах углеводородов, например США. Международное энергетическое агентство (МЭА) с уверенностью заявило, что «Энергетическая безопасность» определяет «уверенность в том, что энергия будет иметься в распоряжении в том количестве и того качества, которые требуются при данных экономических условиях» [3]. Стоит отметить, что энергетическая безопасность характеризуется следующими основными факторами:

- наличием достаточных (доказанных) запасов невозобновимых источников углеводородов, действующих и новых месторождений нефти, газа;

- уровнем развития топливно-энергетического комплекса (ТЭК) государства, способного производить доступные и качественные топливно-энергетические ресурсы (ТЭР);

- уровнем развития топливно-перерабатывающих и других сопредельных производств внутри страны;

- способностью создания энергосберегающих видов производств (страны потребители
ТЭР) с ориентацией на новые виды энергоресурсов и рациональное использование энергоресурсов;

- уровнем устойчивости ТЭК к различного рода «угрозам» (экономических, политических, природно-техногенных), умением ограничить спрос на энергоносители на определенное время, вызванное этими «угрозами».

Европейские государства, испытывающие «острый дефицит» собственных энергетических ресурсов (особенно невозобновляемых) как экономически развитые и естественно потребляющие много энергоресурсов, зависят практически полностью от экспорта нефти и газа, конечно, у них есть возобновляемые источники энергии (ВИЭ), однако они не могут обеспечить полную потребность в энергоресурсах экономику. В этом контексте для стран Европейского союза это явление «Энергетическая безопасность» (a, следовательно, и само определение) необходимо рассматривать также с точки зрения защищенности граждан, государств и их союзов [2]. В этом смысле энергетическая безопасность может трактоваться как «состояние защищенности граждан, общества, государства, экономики от угроз дефицита в обеспечении их потребностей в энергии экономически доступными энергетическими ресурсами приемлемого качества, от угроз нарушений бесперебойности энергоснабжения. При этом состояние защищенности - состояние, соответствующее в нормальных условиях обеспечению в полном объеме обоснованных потребностей (спроса) в энергии, в экстремальных условиях - гарантированному обеспечению минимально необходимого объе- 
ма потребностей [1].

Геополитические и структурные изменения, которые происходили в конце XX века в некоторых европейских странах, СССР, привели к модернизации энергетических отраслей в данных странах, что оказало определенное влияние на энергетическую стабильность Европейского союза [2]. Ввиду сложившейся ситуации возникла необходимость конструировать энергетический диалог с регионами и странами Северной Африки, Центральной и Восточной Европы [4].

Энергетическая политика стран ЕС становится все более политизированной, и как отмечает Т.А. Романова: «Сегодня Брюссель явно рассматривает энергетическое сотрудничество сквозь призму политики и проблем безопасности» [5], что как нельзя лучше иллюстрирует энергетический пакет, принятый на заседании ЕС в 2007 году, создающий систему планирования энергоносителей, сформированную из двух уровней: национального и общеевропейского, которые раз в год подлежат корректировке и обновлению.

Стоит отметить, что зависимость стран Европейского союза составляет $90 \%$ от внешних поставок нефти и 66\% природного газа, а значит, этот вопрос будет одним из прорабатываемых на всех уровнях экономической и политической власти до тех пор пока данные виды энергии будут востребованы. Уязвимость ряда стран в связи с возможными перебоями энергопоставок и изолированность отдельных нефтегазовых рынков, так как поставки осуществляются единственным импортером, представляют потенциальную экономическую и политическую «зону напряженности».

Для решения данных проблем Комиссия ЕС провела ряд тестов, показавших высокий уровень уязвимости внутреннего энергетического рынка как всего Европейского Союза, так и отдельных стран от внешних поставок и потенциальных внешних энергетических кризисов. В частности, было рекомендовано более эффективно координировать энергетическое взаимодействие государств - членов ЕС за счет снятия ограничений на трансграничную торговлю энергией, повысить энергоэффективность и продолжать снижение энергопотребления, реализовать эффективную систему последовательного мониторинга внешних рынков Координационной группой ЕС по газу и нефти [2].

Стоит отметить, что данные совместные за- дачи необходимо решать с позиций энергетического сотрудничества всего европейского региона, однако общих договоренностей по целому ряду вопросов у лидеров стран и энергетических ведомств нет и единого координирующего центра по энергетической безопасности пока не создано, хотя есть ряд организаций и сообществ, прорабатывающих данные вопросы энергетической политики и стабильности, внешнеэкономической деятельности: Комиссия Европейских Сообществ, МЭА.

Согласно статистике «ВР» [6] Европейский союз позиционируется как второй (после США) по уровню импорта энергетических ресурсов субъект, сохраняющий тенденцию роста энергетической зависимости от внешних поставок энергетических ресурсов. Кроме сравнительно высокого уровня потребления, для европейской энергетической системы характерно постоянное снижение сравнительного уровня добычи и производства энергоносителей, что что способствует нарастающему дефициту энергии, и, соответственно, определяет прогнозируемый рост энергетической зависимости ЕС от конъюнктуры мирового энергетического рынка [2].

Однако нельзя не отметить, некоторые реперные точки, которые определяют особенности энергетической безопасности всего европейского региона:

- страны Европейского союза являются крупнейшими импортерами нефти и газа, крупнейшим и приоритетным рынком сбыта для стран-экспортеров углеводородов таких, как: страны Ближнего Востока, России, страны Северной Африки, в частности Алжир;

- находятся в «жесткой зависимости» от экспорта энергоресурсов, а значит и от «поведения» стран-экспортеров, переживают периоды перебоев с поставками;

- не влияют на ценообразование и колебание цен на энергоносители и не имеют эффективных «механизмов» для регулирования этим процессом, порой цены на них не доступны для всех потребителей;

- являются ведущими импортерами энергоресурсов, но вследствие нестабильности цен на энергоресурсы (порой вызванной преднамеренным сговором стран-экспортеров, в частности членов ОПЕК), геополитическими изменениями, изменчивостью валютных курсов или «обвалов» мировых фондовых бирж исключительно уязвимы по всем направлениям энергетической без- 
опасности.

Иными словами, обеспечение стратегии по обеспечению безопасности и бесперебойности поставок энергии - сверхзадача для обеспечения энергетической безопасности стран Европейского союза, рассматриваемая нами с точки зрения надежности поставок и стран-экспортеров, качества ресурсов с соблюдением экологических стандартов, углеводороды по доступным и стабильным ценам для европейских потребителей, привлечения стран-экспортеров нефти и газа на европейский рынок с целью создания здоровой конкуренции, доступа к энергоресурсам третьих стран, а также участия в переговорах по стабилизации цен на энергоносители на мировом рынке.

Необходимость сотрудничества со странами Северной Африки, часть которых являются членами Средиземноморского союза, обуславливается тем, что данный регион является важным поставщиком природного газа и нефти для ЕС, что отвечает запросам для обеспечения энергетической безопасности.

Наиболее развитый топливно-энергетический комплекс стран Северной Африки представлен в Алжирской Народной Демократической Республике в силу исторических, географических и геополитических предпосылок. Алжир является третьим по объему поставок газа в Европу. Стоит отметить, что есть тенденции к дальнейшему развитию данного направления экспорта АНДР (Табл. 1), увеличению протяженности и пропускной способности, подключению к данной сети газопроводов новых участников-стран Европейского Союза.

В данное время на Европейский рынок (основные рынки сбыта Испания и Италия) приходится 95\% экспорта алжирского природного газа. Доказанные запасы природного газа в Алжире составляют 4,5 трлн. кубометров. Эксперты полагают, что эта цифра несколько занижена в результате недостаточной геологической изученности (Российская Федерация предоставляет своих специалистов высочайшей квалификации для оказания помощи в осуществлении геологических исследований) и огромной территории страны (2,4 млн. кв. км, 10 место в мире, 1 место в Африке), а реальные запасы могут достигать 8 трлн. кубометров. Годовая добыча газа в Алжире составляет 93,2 млрд. кубометров (9 место в мире), а наиболее заметное газовое месторождение - Хасси Эрмель. В последнее десятилетие субсидируемые цены на газ (приоритетное направление экономического развития Алжира) значительно увеличили спрос на газ внутри этой аграрной страны, а потребление газа в ней возросло свыше чем на 60\%. (Рис. 1,2 ).

Алжир ежедневно экспортирует более 2 млн. баррелей углеводородов (сырой нефти и сжиженного природного газа) - это 97\% всего экспорта страны, крупнейшим месторождением страны является Хасси Мессауд. Почти весь объем идет в США, Канаду и Западную Европу: Италию, Испанию, Францию, Германию, Бельгию и Нидерланды. Алжирская нефть содержит крайне малое количество серы $(0,05 \%)$ и считается одной из наиболее высококачественных в мире, поэтому европейские НПЗ, учитывая постоянно ужесточающиеся экологические стандарты Евросоюза, предпочитают перерабатывать нефть из Алжира. В данный момент в этой африканской стране работает большое количество иностранных компаний со всего мира: BP, Total, Conoco, ENI, Equinor (бывший Statoil), KUFPEC, Petrobras, CNPC, Anadarko, BHP, CEPSA, ExxonMobil, Lasmo, Maersk, Neste, Oryx, PetroCanada, Repsol, Sasol, Talisman, Wintershall, YPF, Enagas, SNPP, NNPC и ряд других.

Алжирская государственная нефтегазодобывающая компания Sonatrach подписала новые экспортные контракты в 2017 году (сроком на 20 лет) со своими испанскими партнерами - «Сепса», «Эндесеа» и «Ибердола», а также с французской «Газ де Франс Суэз». В отношении поставок на экспорт сжиженного природного газа отмечается сильно обострившаяся с 2011 года конкуренция со стороны США, Катара и Австралии, что привело к серьезному снижению

Таблица 1. Характеристика газопроводов АНДР, взаимодействующих со странами ЕС

\begin{tabular}{|c|c|c|}
\hline Название газопровода & Страна-импортер & $\begin{array}{c}\text { Пропускная способность } \\
\text { млрд. } \mathrm{M}^{3} \text { /год }\end{array}$ \\
\hline Трансмед & Италия & 33,5 \\
\hline Магреб - Европа & Марокко-Испания & 12 \\
\hline Медгаз & Испания & 8 \\
\hline
\end{tabular}

Источник: Составлена автором 


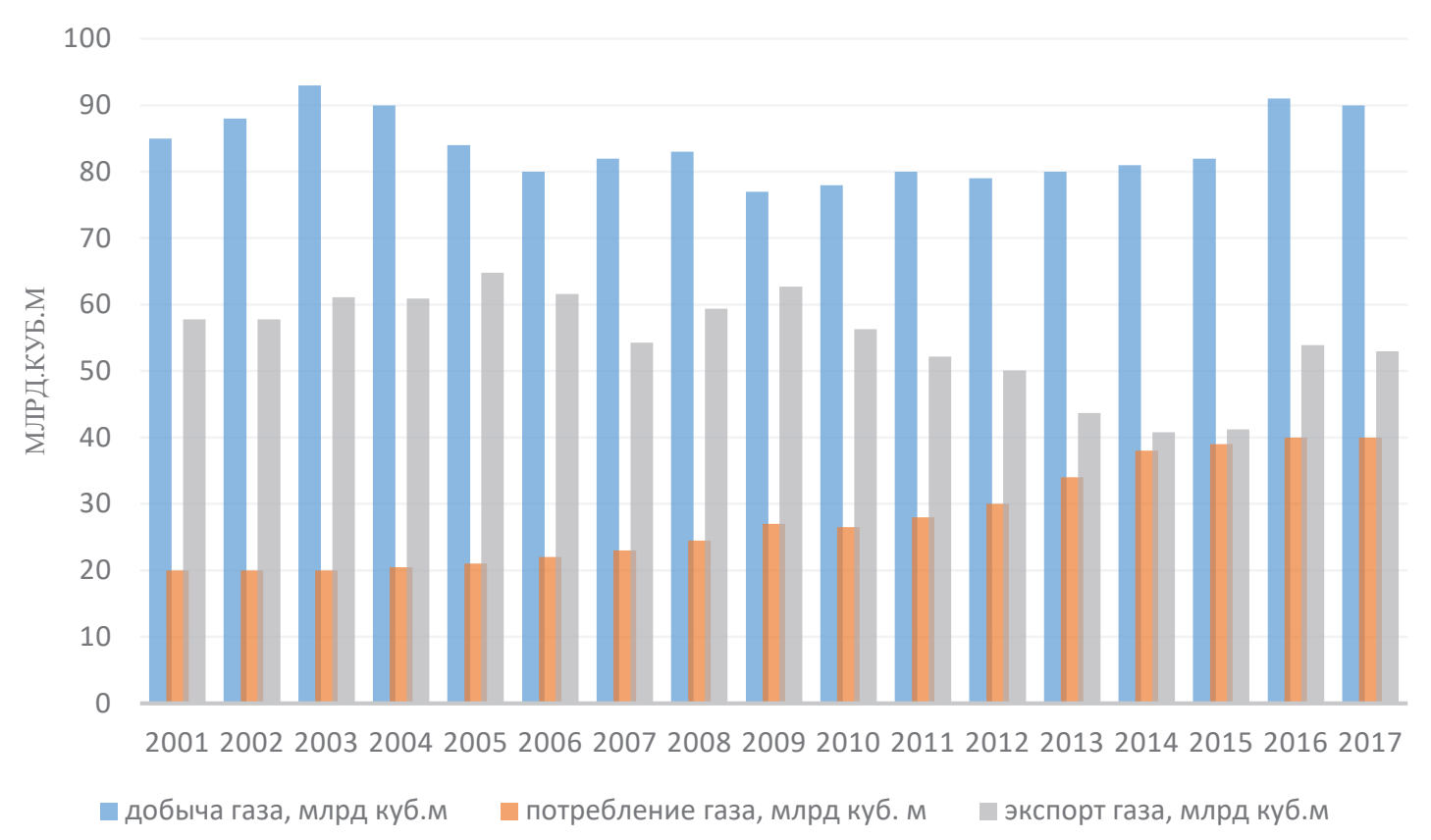

Рисунок 1. Основные показатели газовой отрасли Алжира (2000-2017 гг.) Источник: ВР 2018 год

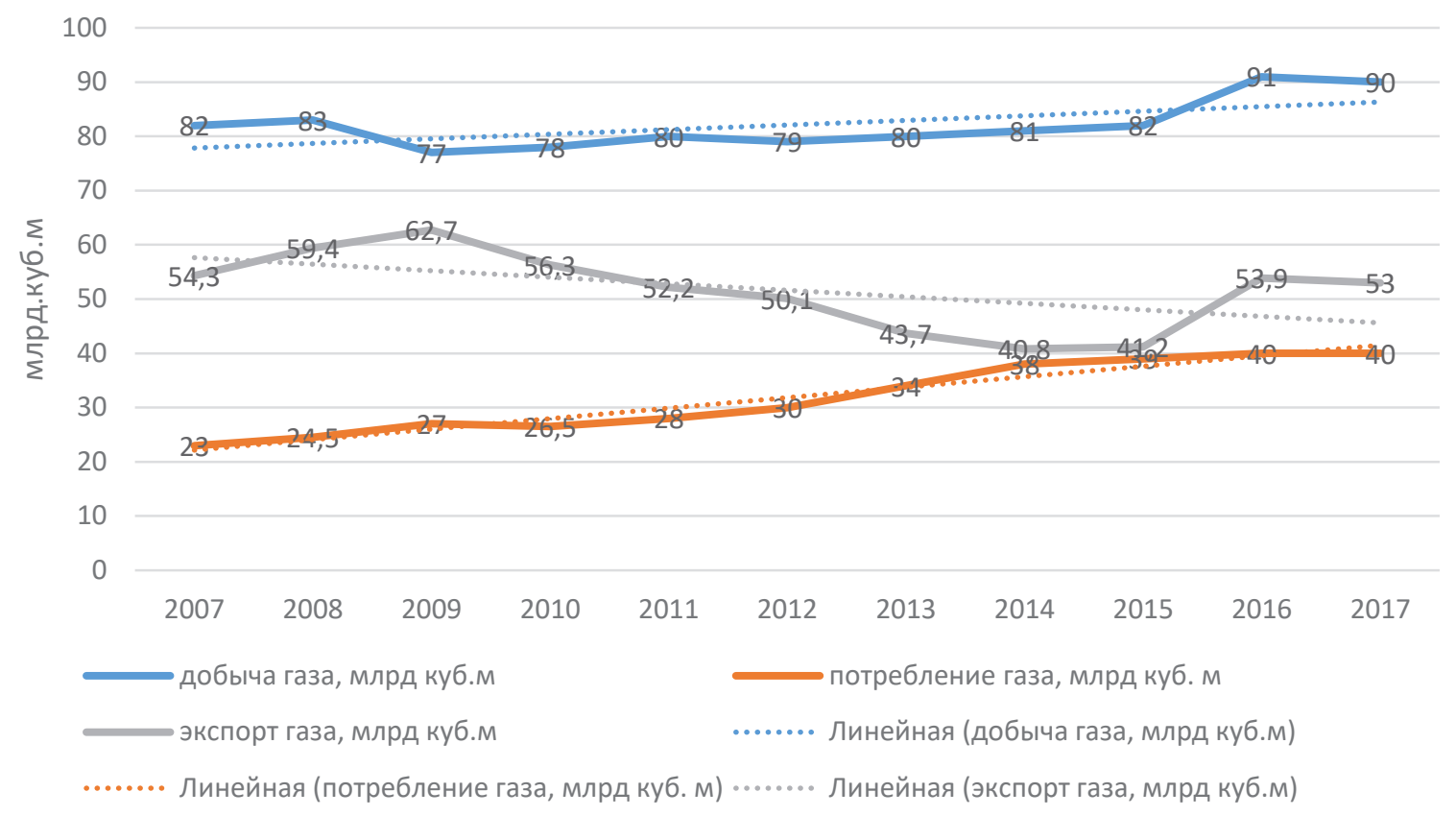

Рисунок 2. Основные показатели газовой отрасли Алжира (2000-2017 гг.) Источник: ВР 2018 год 
процента поставок данного продукта в Европу к 2018 году.

Однако в 2019 году Европейские клиенты компании Sonatrach значительно сократили свой спрос на обычный природный газ из Алжира (Табл.2), что привело к снижению ожидаемого в этом году уровня продаж на $25 \%$, конечно данные изменения имеют политизированный характер.

Снижение экспорта алжирского трубопроводного газа свидетельствует о том, что поставки СПГ от новых производителей от Катара до Нигерии (Табл. 3), а также увеличение экспорта российского природного газа, «давят» на рынок и ведут к снижению цен, что уменьшило конкурентоспособность контрактов на трубный газ из Северной Африки, которые в основном привяза- ны к ценам на нефть. Безусловно, данные колебания на мировом нефтегазовом рынке происходят достаточно часто, но одной из тенденций к стабилизации как раз и является возрастающая потребность стран-членов ЕС в энергоресурсах.

Ввиду растущей зависимости от импорта энергоресурсов создание единой энергетической концепции для союза Европейских стран на мировой арене подразумевает под собой консолидированную внешнюю энергетическую стратегию стран-членов ЕС, для того чтобы иметь особый статус в мировом энергетическом пространстве, и как следствие энергетическую и политическую безопасность, в системе которой Алжирская Народная Демократическая Республика имеет особое значение.

Таким образом, можно говорить о сложив-

Таблица 2. Поставки крупнейших экспортеров природного газа на европейский рынок в 2017-2018 гг., млрд. $\mathbf{m}^{3}$

\begin{tabular}{|c|c|c|c|c|}
\hline & $\mathbf{2 0 1 7} \mathbf{~ . ~}$ & $\mathbf{2 0 1 8} \mathbf{~ . ~}$ & $\begin{array}{c}\text { Изменения } \\
\left.\text { (млрд. } \mathbf{M}^{3}\right)\end{array}$ & Изменения (\%) \\
\hline ПАО «Газпром» & 194,4 & 201,8 & 7,4 & 3,8 \\
\hline Алжир (вкл. СПГ) & 49,4 & 48,4 & $-1,0$ & $-2,0$ \\
\hline Катар & 24,1 & 23,4 & $-0,7$ & $-2,9$ \\
\hline Нигерия & 12,6 & 13,1 & 0,5 & 4,0 \\
\hline Иран & 9,6 & 8,0 & $-1,6$ & $-16,7$ \\
\hline
\end{tabular}

Источник: Обзор Европейского рынка газа ПАО «Газпром» 2019 год. https://www.gazprom.ru/press/news/reports/2019/european-gas-market/

Таблица 3. Поставки СПГ на европейский рынок в 2017-2018 гг., млрд. м³

\begin{tabular}{|c|c|c|c|c|}
\hline Название страны & 2017 г. & 2018 г. & $\begin{array}{c}\text { Изменения } \\
\left.\text { (млрд. } \mathbf{m}^{3}\right)\end{array}$ & Изменения (\%) \\
\hline Катар & 24,1 & 23,4 & $-0,7$ & $-2,9$ \\
\hline Нигерия & 12,6 & 13,2 & 0,6 & 4,8 \\
\hline Алжир & 14,3 & 13 & $-1,3$ & $-9,1$ \\
\hline Россия («Ямал СПГ») & 0,1 & 6,7 & 6,6 & 6600,0 \\
\hline США & 2,6 & 3,7 & 1,1 & 42,3 \\
\hline Тринидад и Тобаго & 1,8 & 3,6 & 1,8 & 100,0 \\
\hline Норвегия & 3,9 & 3,6 & $-0,3$ & $-7,7$ \\
\hline Перу & 4,1 & 2,6 & $-1,5$ & $-36,6$ \\
\hline Египет & 0,3 & 0,9 & 0,6 & 200,0 \\
\hline Ангола & 0,6 & 0,7 & 0,1 & 16,7 \\
\hline Экваториальная Гвинея & 0,4 & 0,4 & 0 & 0,0 \\
\hline Бразилия & 0,08 & 0 & $-0,1$ & $-100,0$ \\
\hline Доминиканская Республика & 0,04 & 0 & $-0,04$ & $-100,0$ \\
\hline Литва (ре-экспорт) & 0,01 & 0 & $-0,01$ & $-100,0$ \\
\hline Итого & 64,9 & 71,8 & 6,9 & 10,5 \\
\hline
\end{tabular}

Источник: Обзор Европейского рынка газа ПАО «Газпром» 2019 год. https://www.gazprom.ru/press/news/reports/2019/ european-gas-market 
шейся системе приоритетных задач, стоящих перед энергетической безопасностью Европейского союза. На фоне объявленной пандемии коронавируса COVID-19 (Всемирная Организация Здравоохранения, 13.03.2020 г.) и признания Европы ее эпицентром, мировыми экспертами прогнозируется резкий спад экономики прак- тически во всех европейский государствах, где уровень заболеваемости и процент смертности достаточно высок. На наш взгляд, подобные вызовы расставят приоритеты в вопросах о более дешевых энергоресурсах для ЕС, что готов предоставить Алжир и другие страны-экспортеры газа и нефти.

\section{Библиографический список}

1. Воропай Н.И., Сендеров С.М. «Энергетическая безопасность: сущность, основные проблемы, методы и результаты исследований». М.2011.-С.91.

2. Григорьева О.В. «Энергетическая дипломатия стран Северной Европы: процесс становления и перспективы развития» Режим доступа: https://disser.spbu.ru/files/disser2/783/aftoreferat/NgyLHtnk0Z.pdf (дата обращения 20.02.2018).

3. Игишева Е.А., Морий С.М. «Энергетическая безопасность в современном мире: основные подходы к изучению». Известия УрГЭУ РАН № 5, 2014.-С. 4 Режим доступа: https://ecfor.ru/wp-content/uploads/seminar/ energo/z119.pdf

4. Keukeleire, S., Mac. Naughtan J. The Foreign Policy of the European Union.- Basingstoke: Palgrave Macmillan, 2008.- P. 14-15.

5. Романова Т. А. «Третий пакет» и будущее «Газпрома». // Россия в глобальной политике. 2007. № 6. Режим доступа: http://www.globalaffairs.ru/number/n_9959 (дата обращения: 10.10.2016).

6. British petroleum annual report 2018 (Источник: https://www.bp.com/content/dam/bp/business-sites/en/global/ corporate/pdfs/investors/bp-annual-report-and-form-20f-2018.pdf). 